\title{
Educação e religião Guarani no Paraná: estudo a partir do ritual Nimongarai*
}

\section{Guarani education and religion in the state of Paraná, Brazil: a study on the Nimongarai ritual}

\author{
Rosangela Celia Faustino*
}

\begin{abstract}
Resumo: Com a violenta expropriação e mercantilização dos territórios paranaenses, os grupos indígenas sobreviventes foram, no início do século XX, reunidos em pequenas parcelas de terras, as aldeias, hoje chamadas Terras Indígenas (TIs). Como consequência, os Guarani no Norte do Paraná, que atualmente habitam as TIs Laranjinha, Ywy Porã e Pinhalzinho, por falta de terra, vivem em situação precária, sofreram e sofrem a perda de boa parte das tradições culturais, incluindo a língua materna. Nos anos de 1980 e 1990, no contexto da crise econômica mundial e de intensos movimentos sociais, organismos internacionais como a UNESCO e Banco Mundial reafirmaram a importância das culturas minoritárias e iniciaram, em parceria com os Estados nacionais, a implementação de políticas de inclusão, baseadas no direito à diferença. Neste texto são apresentados e discutidos os resultados de um projeto de revitalização cultural desenvolvido por meio do registro de narrativas dos velhos, do ritual de batismo Nimongarai e de intervenções pedagógicas em escolas indígenas Guarani do Paraná.
\end{abstract}

Palavras-chave: Educação indígena. Guarani Nhandewa. Nimongarai.

\begin{abstract}
Due to the violent expropriation and commercialization of large areas in the state of Paraná, Brazil, at the beginning of the $20^{\text {th }}$ century the surviving indigenous groups were herded within small parcels of land, called villages, and currently denominated Indigene Land (IL). The Nhandewa Guarani of the northern region of the state of Paraná, living in the Laranjinha, Ywyporã and Pinhalzinho ILs, have experienced terrible conditions since they lost many of their traditions and culture, including their language. During the 1980s and 1990s and within the context of the world economic crisis, the international organisms UNESCO and World Bank aimed at social cohesion and started, as a joint venture with the national states, the implementation of an inclusion policy based on the right to be different. Current analysis discusses the results of a cultural revival project developed through the register of narratives by the indigene elderly people with regard to the Nimongarai baptism ritual and pedagogical interventions in schools in the state of Paraná.
\end{abstract}

Keywords: Indigenous education. Guarani Nhandewa. Nimongarai.

\footnotetext{
* O projeto que deu origem ao texto, se intitula: Ouvir dos velhos, contar aos jovens: memórias, histórias e conbecimentos Guarani Nhandewa no Paraná. No período de 2009 e 2010 recebeu financiamento do Programa Universidade Sem Fronteiras - SETI-PR tendo sido continuado nos anos de 2011 e 2012 com o apoio do Programa Observatório da Educação Escolar Indígena - CAPES/DEB/INEP. Edital 01/2009.

** Docente da Universidade Estadual de Maringá. Coordenadora do Observatório da Educação Escolar Indígena/UEM. E-mail: <rofaustino@terra.com.br>
} 


\section{Introdução}

O processo de expropriação e venda das terras do Paraná dizimou grupos e etnias indígenas que habitavam estes territórios. Os indígenas, segundo Nimuendaju (1987) e Bartolomé (1991), deslocaram-se, lutaram e resistiram ao extermínio, e assim os sobreviventes foram reunidos em pequenas parcelas de terras denominadas pelo Serviço de Proteção ao Índio (SPI), reservas ou aldeias. Este órgão, fruto das reformas republicanas (GAGLIARDI, 1989), teve como objetivo principal pacificar e civilizar os índios que apresentavam resistência às frentes de colonização capitalista.

[...] tratava-se de atrair e pacificar, conquistar terras sem destruir os ocupantes indígenas, obtendo-se assim, a mão de obra necessária à execução dos ideais de Couto de Magalhães, de desbravamento e preparação das terras não colonizadas para posterior ocupação definitiva [...]. (GIROTTO, 2007, p. 17).

Nas aldeias do Paraná foram alojados indígenas de diferentes etnias e implementou-se o sistema de lavouras coletivas, criação de animais domésticos para consumo e comércio do excedente com o objetivo de introduzir os grupos indígenas em relações mercantis, a chamada integração. Concomitantemente a isso foram sendo implementados projetos instrucionais que visavam ao ensino da língua portuguesa, noções de higiene e costumes nacionais, configurados pela educação moral e cívica e formação profissional em carpintaria, práticas agrícolas, corte e costura, etc.

Estimulou-se a prática de religiões cristãs e dos casamentos interétnicos para a miscigenação e diminuição das diferenças entre índios e não índios. Separam-se famílias e grupos familiares, "[...] algumas crianças eram enviadas para as escolas de artífices existentes nas capitais estaduais [...]”. (RIZZINI, 2004 apud PACHECO DE OLIVEIRA; FREIRE, 2006, p. 124). Estas instituições de assistência à infância de crianças "carentes" foram criadas no século XIX, no Segundo Império. A Escola de Aprendizes e Artífices do Paraná, inaugurada em 1910, recebeu crianças indígenas.

Nas aldeias, são muitos os relatos de invasões, perseguições, expulsões e assassinatos de grupos indígenas, tanto na documentação histórica como na memória dos mais antigos. Os estudos de Mota (1998) e Mota e Noelli (1999) mostram que, no Paraná, as aldeias criadas para apaziguar e pacificar as resistências indígenas no início do século XX foram invadidas, e depois, no final da década de 1940, drasticamente reduzidas por meio de acordos entre o Governo e latifundiários. Nesse processo, os indígenas continuaram lutando, mas perderam grande parte do que havia sido demarcado nos acordos do início do século. 
Os relatos orais de velhos indígenas evidenciam ter sido a vida nas aldeias muito difícil, com trabalho forçado, castigos físicos, restrições à liberdade de ir e vir, pobreza e impedimento da prática da cultura tradicional, já golpeada pela drástica redução dos territórios e desmatamento do entorno. As formas de trabalho, a religião, as curas, a alimentação, a educação das crianças, enfim, todos os conhecimentos milenares produzidos, acumulados e disseminados pelos grupos indígenas por seus próprios meios, foram reprimidos em nome da civilização.

No final do século XX, mais precisamente nas décadas de 1980 e 1990, em um contexto de crise econômica internacional e de grandes protestos sociais com vistas à coesão social, os organismos internacionais elaboram uma política de inclusão social destinada às populações em situação de vulnerabilidade, propondo o reconhecimento e o respeito à diversidade cultural. A educação, principal alvo das propostas, foi reformulada. As políticas envolveram as universidades, instadas a participar do processo, instituindo formas de ingresso de estudantes indígenas no Ensino Superior e de desenvolvimento de extensão e pesquisas na área.

O presente texto tem como objetivo apresentar os resultados de um projeto, elaborado a partir de um pedido dos professores indígenas Guarani Nhandewa, habitantes de terras indígenas no Norte do Paraná, de que gostariam de realizar, com o apoio da Universidade Estadual de Maringá - UEM, um trabalho de revitalização cultural que resultasse em material escrito e em áudio para trabalho nas escolas indígenas.

\section{Os Guarani Nhandewa no Norte do Paraná}

Os Guarani pertencem à família linguística tupi-guarani e se dividem nas parcialidades ou subgrupos Nhandewa, Mbya e Kaiowa (SCHADEN, 1982; ALMEIDA; MURA, 2003). Eles constituem um numeroso grupo étnico que habita diferentes regiões da América Latina, como o Brasil, o Paraguai, o Uruguai, a Bolívia e a Argentina. Em relação à realidade territorial, cultural e linguística dos grupos não existe um padrão. Além das parcialidades há diferenças que dependem do histórico da demarcação das terras, das lutas e das políticas locais.

O estudo de Faustino (2006), fazendo uma trajetória da presença dos Guarani no Paraná, mostra que os grupos dessa etnia têm em torno de 4.000 (quatro mil) pessoas. Atualmente, a situação fundiária no Estado evidencia existirem dezoito terras indígenas demarcadas, seis em processo de regularização e treze não regularizadas, totalizando 37 TIs (ESTRATÉGIA... 2012), nas quais vivem índios Guarani, Kaingang e Xetá. Nas TIs os grupos são constantemente ameaçados por disputas de titularidade, danos ambientais, exploração ilegal de recursos naturais, projetos de construção de hidrelétricas, ocupação por terceiros e expulsões. 
Um exemplo do que tem acontecido com as áreas demarcadas é a TI Ocoy, destruída pela construção da hidrelétrica Itaipu. Tendo o desvio do curso das águas inundado quase toda a TI, afetou violentamente a fauna e a flora locais, provocando extremas dificuldades às famílias Guarani com a falta de alimentos, subnutrição, falta de trabalho e impossibilidade das práticas religiosas que envolvem o meio ambiente. A situação foi vivenciada com muita luta por mais de quinze anos para que tivessem nova terra regularizada e pudessem reiniciar o processo de consagração do território, o tekoá e revitalização do teko, a cultura.

As terras demarcadas para os Guarani no Norte estão situadas nos municípios de mais baixo IDH (índice de desenvolvimento humano), rodeadas pela agricultura mecanizada com alta utilização de agrotóxicos. Os rios estão poluídos e há pouquíssimas reservas de matas, pois o estado figura entre os de maior área desflorestada na Região Sul. Segundo estudos do ITCG (Instituto de Terras, Cartografias e Geociências), o Paraná apresenta desmatamento de mais de 90\% de suas florestas, e o que resta é um índice inferior ao mínimo exigido para a conservação da biodiversidade.

A pesca, a caça, e coleta e produção de artesanato, em decorrência da falta dos recursos naturais (taquara, sementes, plumas), são incipientes entre os grupos. Nas áreas demarcadas, além do solo degradado, a extensão da terra não é suficiente para a prática da agricultura. Com a falta de trabalho, muitas famílias e jovens solteiros migram para as cidades maiores em busca de sobrevivência.

Em decorrência desse histórico, a maior parte dos grupos Guarani no Paraná tem a língua portuguesa como língua materna, como é o caso dos Nhandewa do Norte; porém nas comunidades sempre há falantes, principalmente alguns velhos. Os jovens e crianças, embora não falantes, pronunciam e entendem várias palavras, expressões, cantos e rezas. Os professores, especialmente quando pertencentes aos grupos familiares dos txamói, sábios, rezadores, atuam na busca da revitalização da cultura e da língua. Em uma rede de trocas estabelecida com outros grupos das diferentes parcialidades, vão implementando, por meio de práticas comunitárias e na escola, ações que contemplem elementos de sua cultura.

Na TI Laranjinha, município de Santa Amélia - PR, habita um grupo com cerca de 350 (trezentas e cinquenta) pessoas em uma área de 284 hectares. Com o solo desgastado, a extensão insuficiente para as roças de todas as famílias, as dificuldades em conseguir sementes, fertilizantes e maquinários (arado, trator), as pessoas vivem de trabalhos temporários que buscam fora da TI, de aposentadorias recebidas pelos velhos e de alguns empregos públicos (professor, agente de saúde, motorista, auxiliar de serviços gerais); porém estas atividades atingem menos de $10 \%$ da população. Os demais dependem da assistência do Estado (bolsa-família, cestas básicas) e buscam trabalho nas cidades. 
Na comunidade há uma escola, denominada Escola Estadual Cacique Tudjá Nhanderu, que oferece Educação Infantil e os anos iniciais do Ensino Fundamental de nove anos. Os professores que nela atuam são índios e não índios. Em 2010 uma pedagoga indígena formada pela UEM assumiu temporariamente a função de Professor Pedagogo por meio do PSS (Processo de Seleção Simplificado).

Na TI Pinhalzinho, município de Tomazina - PR, a população é de cerca de 160 pessoas, em uma área de 593 hectares. O estudo de Dreminski (2011, p. 44) evidencia que esta TI, demarcada pela FUNAI em 1986, nunca teve condições de garantir a reprodução social e cultural ao grupo, sobretudo porque já se encontrava degradada por fazendeiros de gado quando da demarcação. O estudo mostra que a área é cercada e sempre esteve ocupada por monoculturas de soja, pastagens e eucaliptos, numa convivência forçada no interior da aldeia, nos últimos 25 anos, pela presença de grileiros que somente foram retirados mediante ação judicial, em 2009. Essa situação levou os indígenas a diversos conflitos e lhes impediu o acesso a várias áreas dentro da aldeia, reduzindo-lhes a possibilidade de realizar suas práticas extrativistas tradicionais.

Nesta comunidade há uma escola de denominada Escola Estadual Indígena Y wy Porã, que atende crianças dos anos iniciais e finais do Ensino Fundamental e na qual atuam professores índios e não índios e estudam cerca de 40 crianças Guarani.

A situação da TI Ywy Porã (Posto Velho), município de Abatiá - PR, é mais precária, pois a área, de 1.238 hectares, não está demarcada e nela vivem cerca de 140 pessoas sem nenhuma condição de reprodução da vida e em constante beligerância com os fazendeiros vizinhos, que só aceitaram a presença indígena no local por força de acordo judicial. No relato dos moradores mais velhos evidencia-se que a área havia sido destinada pelo Governo aos Guarani nos acordos do início do século XX, mas foi invadida e eles foram perseguidos e expulsos. As últimas famílias que resistiram foram forçadas a sair no final dos anos de 1960 e se alojaram na TI Larajinha, área vizinha, e na TI Araribá, município de Bauru - SP e outras se dispersaram pelas cidades do entorno.

No ano de 2005 houve a reorganização para a reocupação de parte dessa terra antiga. O grupo, de cerca de 100 pessoas, ocupou casas e paióis desativados da fazenda que havia sido instalada sobre aquela TI. Os fazendeiros reagiram violentamente à retomada. Com a intervenção da justiça os indígenas permaneceram, porém o abastecimento da água foi suspenso, não podem fazer roças, ou extrair recursos naturais da terra (nem mesmo o sapé para fazer a casa de reza). Não há água potável. Um riacho nas proximidades recebe dejetos da lavoura mecanizada das fazendas. Não há saneamento ou banheiros. A FUNAI (Fundação nacional do Índio), com poucos recursos, presta uma assistência 
mínima ao grupo. Homens e rapazes solteiros buscam trabalho fora, mas não o conseguem nas proximidades, devido a um acordo tácito entre a classe dominante de não empregar mão de obra indígena na região.

Os índios construíram uma opygatsu, casa de reza ou casa grande, que ficou inacabada por falta de matéria-prima. Algumas danças e celebrações são feitas em um pátio aberto. Os professores existentes entre o grupo conseguiram uma lona e fizeram uma escola, que chamaram de Nimboeaty Mborowitxa Awa Tirope, de taquara e chão batido, para ensinar a língua guarani e conteúdos escolares às crianças. A SEED-PR registrou-a como Escola Estadual Indígena Nimboeaty Mborowitxa Awa Tirope, transferindo-a para um cômodo precário de madeira disponível no local. Estando aquela terra em litígio, não há como licitar e construir com recursos públicos. O cômodo destinado à "escola" é usado como sala de aula, refeitório, secretaria e depósito. Há sete anos o grupo resiste nestas condições, sem que a questão da terra seja resolvida. Essa situação de extrema carência afeta o trabalho de revitalização cultural na escola.

Nas escolas os professores indígenas não são concursados. Atuam como temporários e são contratados e recontratados pelo sistema do PSS (Processo de Seleção Simplificado). Os currículos são semelhantes aos currículos das demais escolas do País, com a inclusão da língua indígena na grade curricular. Nem todos os professores indígenas têm o domínio da língua na oralidade e escrita. Por não estar nas relações cotidianas dos grupos, a maior parte dos professores dela só conhecem os rudimentos. A rotatividade e instabilidade vivenciadas pelos professores, causadas tanto pela forma de contratação como por fatores internos, inviabilizam a elaboração de projetos de longo prazo. O PIESP/LAEE/ UEM - Programa Interdisciplinar de Estudos de Populações, Laboratório de Arqueologia, Enologia e Etno-História da Universidade Estadual de Maringá - tem proposto ações de curta duração (máximo de um semestre) para que os projetos possam ser realizados com o mesmo grupo de estudantes e professores.

\section{O indígena e as políticas públicas de inclusão}

Relacionada diretamente às políticas públicas governamentais, a educação escolar para os indígenas tem um longo histórico. Grizzi e Silva (1981, p. 16) chamam a atenção para o fato de que "[...] a educação para o índio jamais é neutra e qualquer projeto está sempre orientado por uma política básica [...]." Historicamente, implementou-se um projeto colonizador e integracionista, no qual a educação ocupou-se de instruir os indígenas para a aceitação da política do colonialismo e de adesão ao mercado de trabalho.

Faustino (2006, p. 29) observa que desde o século XVI a política educacional foi concernente ao modelo de exploração conduzido pelas 
economias dominantes, com caráter moralista, noções de civilidade, ordem, disciplina, respeito à hierarquia e obediência aos dogmas econômicos do sistema de mercado.

Salienta-se a pouca ou nenhuma relevância da cultura das populações indígenas para os agentes colonizadores e suas instituições. Na metade do século XVIII, em meio à crise do mercantilismo, as reformas políticas do Estado, conduzidas por Marques de Pombal (ministro Sebastião José de Carvalho e Melo), objetivando minimizar o poder da Igreja com vistas a salvar Portugal da crise europeia, tentou-se colocar a escola a serviço dos interesses do Estado. Em relação à educação escolar indígena, o objetivo foi a "[...] extinção das diferenças entre índios e brancos" (GARCIA, 2007, p. 24). O processo pautou-se principalmente pelo combate às práticas culturais, com especial atenção à substituição da língua indígena pela língua portuguesa. Mota (1998, p. 3), ao analisar a situação no Paraná colonial (1853-1889), indica que "Para realização dessa dominação, os conquistadores recorrem tanto à força como a um conjunto de valores, normas e comportamentos".

Na passagem do século XIX ao XX, nas primeiras décadas os positivistas, instalados no poder, defendiam políticas mais "brandas" de tratamento aos índios, considerando que eles poderiam, com base nos estudos de Auguste Comte, ser promovidos do estado primitivo em que viviam para o estado da civilização. Nesse sentido, as culturas dos povos indígenas foram situadas em patamares inferiores, do ponto de vista da ciência moderna, sendo obstáculos, para os próprios indígenas, ao acesso a formas mais elaboradas e adequadas de pensamento. Assim, extingui-las seria uma consequência natural, já que dos indígenas não se sabia o passado e a assimilação era vislumbrada como o único futuro (MOTA, 1998).

Demonstra-se assim que o caráter civilizatório eurocentrista da educação destinada às regiões exploradas não se alterou, apesar das transformações políticas significativas da sociedade brasileira no decorrer do século XX (proclamação da República, abolição da escravidão, industrialização, etc.). Na educação desse século a instituição evangélica Summer Institute of Linguistics (SIL), que já vinha atuando em países da América Latina (BARROS, 2004), para a conversão indígena, conseguiu entrar e se instalar no Brasil nos anos de 1960.

Tendo o SPI sido extinto na segunda metade do século XX, em seu lugar o governo militar instituiu a FUNAI, reafirmando os objetivos da política de pacificação, instrução, civilização e integração indígena. O governo militar, por meio da FUNAI, passou a coordenação da educação escolar indígena ao SIL no início dos anos de 1970.

Nesse mesmo período inicia-se uma crise econômica internacional de grandes proporções, cujos resultados atingiram diferentes partes do mundo nos 
anos de 1980 e 1990 . Os desdobramentos da crise do sistema capitalista são, principalmente, o desemprego em massa, grandes processos migratórios (CUCHE, 1999), greves, protestos, criação de partidos de esquerda e fortalecimento do sindicalismo, fatores que forçaram o sistema, via centros de poder, à adoção de reformas, ampliação da democracia liberal e implementação de políticas públicas voltadas ao aliviamento da pobreza dos grupos mais vulneráveis.

Tendo como exemplo de medidas adotadas e bem-sucedidas de controle de movimentos de protestos e de minorias no Canadá, nos Estados Unidos e em países da Europa Central nos anos de 1970 e 1980, os organismos internacionais optaram por uma política internacional de tolerância, multiculturalismo e interculturalidade (FAUSTINO, 2006), elaborando um projeto de inclusão baseado no reconhecimento da diversidade cultural. Esta política foi conduzida, principalmente, pela UNESCO - Organização das Nações Unidas para a Educação, a Ciência e a Cultura (ONU, 1999) e pelo Banco Mundial (BENGOA, 1993).

La comunidad internacional considera que es su deber velar por la preservación y la defensa de la identidad cultural de cada pueblo. Todo ello invoca políticas culturales que protejan, estimulen y enriquezcan la identidad y el patrimonio cultural de cada pueblo; además, que establezcan el más absoluto respeto y aprecio por las minorías culturales, y por las otras culturas del mundo. (UNESCO; CEPAL; OEA, 1979, p. 24).

Tendo participado de convenções, conferências, tratados, relatórios e acordos internacionais, os países membros da ONU se comprometeram a elaborar reformas em suas cartas constitucionais com vistas ao desenvolvimento de uma política de inclusão destinada aos grupos mais vulneráveis e às minorias étnicas. No Brasil, a partir do final dos anos de 1980 essa política se destinou, principalmente, aos indígenas, afrodescendentes e deficientes.

É importante observar que no contexto dessa política, ao mesmo tempo em que os movimentos dos trabalhadores foram duramente reprimidos (FAUSTINO 2006), os movimentos das chamadas minorias foram consentidos e a eles se atribuiu ampla conotação cultural e identitária (HUNTINGTON, 1993).

Permitiu-se às minorias

[...] desfrutar de suas próprias culturas, professar e praticar suas próprias religiões, utilizar suas próprias línguas, em público e no privado, livremente, sem ingerência e discriminação de nenhuma forma [...] estabelecer e manter suas próprias associações [...] manter contatos livres e pacíficos com outros membros de seus grupos e outras minorias assim como, contatos transfronteiriços com pessoas de outros Estados com que tenham vínculos étnicos, religiosos ou linguísticos. (ONU, 1992). 
Em relação à educação bilíngue, desde os desdobramentos finais das grandes guerras mundiais (a criação dos organismos e agências internacionais, ações da guerra fria e as medidas para conter os movimentos socialistas no mundo), determinou-se: "Será ministrado às crianças pertencentes às populações interessadas, ensino para capacitá-las a ler e escrever em sua língua materna [...]" (OIT, 1957, Art. 23, p. 2). No contexto da crise econômica internacional e dos vertiginosos movimentos sociais, reafirmou-se que "[...] a educação na língua própria das minorias é um componente essencial para proteger suas identidades" (ONU, 1992, p. 4).

No Brasil, na década de 1990, todos os documentos (Diretrizes Curriculares para a Educação Escolar Indígena, Lei de Diretrizes e Bases da Educação, Referencial Curricular Nacional para as Escolas Indígenas e outros) acatam essas deliberações internacionais e por elas se orientam. Por sua vez, as secretarias estaduais de Educação reafirmaram essas deliberações transformando-as em Planos Estaduais de Educação (PARANÁ, 2005). Organizou-se a formação dos professores e equipe pedagógica no sentido de mobilizar as escolas indígenas para a elaboração de PPP (Projetos Político-Pedagógicos) e currículos com referência à interculturalidade e ao bilinguismo.

As ações afirmativas, também provenientes da política internacional de inclusão e diversidade cultural (FAUSTINO, 2006), possibilitaram o acesso de estudantes indígenas ao ensino superior a partir da década de 1990. Nesse contexto, as universidades passaram a ter maior inserção de pesquisas e extensão, com financiamentos, o que possibilitou o desenvolvimento de ações mais efetivas em relação à educação escolar em terras indígenas.

\section{O projeto de revitalização cultural Guarani Nhandewa}

Em 2007, professores Guarani das terras indígenas no Norte do Paraná procuraram o PIESP/LAEE-UEM-PR, que desde 1996 desenvolve ações junto aos povos indígenas no Estado, e solicitaram apoio para a elaboração de materiais didáticos que contemplassem aspectos das tradições Guarani. Argumentaram sobre a importância de trabalhar com a cultura na escola, afirmando que alguns jovens, atraídos pelas “coisas dos brancos", estão demonstrando pouco interesse nas tradições e língua indígena. Evidenciaram preocupação com a devastação do ambiente (poluição, desmatamento) e com o fato de os mais velhos, sábios das comunidades, estarem, alguns, já doentes e sem apoio para levar adiante as práticas culturais tradicionais.

Em relação à escola indígena, apontaram a falta de estrutura adequada para o trabalho dos professores de forma geral e especialmente dos professores indígenas, que precisam trabalhar com a língua e a cultura indígena. 
Estudos e documentos corroboram o que os professores indígenas alegam:

[...] a situação das populações indígenas é de desproteção, seja pela ausência de políticas direcionadas a essas populações, ou pela desorganização dos modos de produção de subsistência tradicionais, advinda do contato e das pressões ocasionadas pelas frentes de expansão da sociedade nacional brasileira. (CIMI, 2006, p. 23).

O documento assevera que a falta de perspectiva para os jovens nas aldeias está associada ao alcoolismo, ao uso de drogas, a crimes e agressões, à gravidez precoce e, muitas vezes, a dificuldades de permanência na escola. A taxa de analfabetismo é outro dos indicadores que expressam as desigualdades étnicas. "[...] 26\% da população indígena acima de 15 anos é analfabeta, enquanto 20\% dos negros e 8\% dos brancos estão na mesma situação”. (CIMI, 2006, p. 27).

A difícil vida nas aldeias e a falta de perspectivas em um ambiente devastado deixam os mais velhos, as lideranças, famílias e os professores indígenas preocupados com o futuro dos jovens e crianças, mobilizando-os na busca de possibilidades e alternativas.

Considerando a orientação teórica da área de educação do PIESP/ LAEE/UEM, baseada na Teoria Histórico-Cultural, na qual Vigotski, seu principal precursor, afirma a importância da cultura nos processos de aprendizagem e desenvolvimento, avaliamos ser viável o trabalho nessa perspectiva.

Com a publicação, em 2008, de um Edital da SETI-PR, Secretaria de Estado da Ciência, Tecnologia e Ensino Superior, por meio do Programa Universidade Sem Fronteiras, destinado ao desenvolvimento de projetos de extensão abrangendo populações de municípios de baixo IDH, foi elaborado e aprovado o Projeto intitulado Ouvir dos velhos, contar aos jovens: memórias, histórias e conbecimentos guarani nhandewa no Paraná, com vigência nos anos de 2009 e 2010 . Na sequência, com o programa Observatório da Educação, implementado pela CAPES/INEP/DEB, foi possível dar continuidade às ações com os Nhandewa.

Como nas TIs no Norte do Paraná a língua guarani é conhecida e falada, como segunda língua pelos tudjá velhos, tentativas são feitas pelos grupos em diferentes momentos, no sentido de reaprender e não perder a língua. Em Iwy Porã o professor Claudinei Alves, que foi criado na TI Curt Nimuendaju (antiga TI Araribá), e por isso fala a língua, ministra periodicamente cursos de guarani para os interessados na comunidade.

Segundo professores, txamói, rezadores e lideranças (FAUSTINO 2006), ter empenho em aprender a língua está relacionado ao interesse pelos conhecimentos tradicionais. Em 2005 quase todas as pessoas que participaram de um destes cursos integraram um grupo de retomada de terras tradicionais, 
o Posto Velho, município de Santa Amélia - PR, fundando ali a TI Ywy Porã. Lá chegando iniciariam ações de revitalização, com a orientação de só falar com as crianças em Guarani e solicitar delas que respondessem na mesma língua, retomar o que era possível da alimentação tradicional (milho, palmito, batata-doce, mandioca, amendoim, carne de caça, mel), construir uma opy, casa de reza e fundar uma escola onde as crianças aprenderiam os conhecimentos universais e a língua guarani escrita.

Conforme entrevista realizada com o senhor Bertolino Rodrigues, um dos mais velhos da TI Laranjinha, que foi professor, cacique e txamói, rezador,

[...] Tem que ter escola para aprender o que vão precisar para viver no mundo. Se ficar só entre nós, com o nosso conbecimento não vai dar, vão sofrer igual nós sofremos. Nosso conhecimento e a linguagem quando usava é só entre nós mesmo e agora quase não usa mais, já pegou a do outro. (FAUSTINO, 2006).

A escola é tida pelos Guarani do Norte do Paraná como uma instituição capaz de ajudá-los a diminuir o preconceito que sofrem:

[...] o branco, ele discrimina o indio por causa de não ter estudo no passado. A discriminacãa aumenta e a partir do momento que o indio entra numa escola, ele é reconhecido também, porque o branco sabe que o que manda é o discurso, então por isso hoje, as áreas indígenas, como elas tá mais próximo da cidade, tá próximo não porque o indio quer, mas porque o branco foi chegando, não tem como então o indio estudando, ele vai ter autonomia para conversar, porque senão a discriminação vai continuar sempre assim, e eu acredito que no futuro a população indigena vai ter discriminação, mas vai ser menos, vai diminuindo aos poucos [...]. (Olívio Jekupe. Ex-professor da T.I. Laranjinha, depoimento publicado em MOTA, 2000, p. 21).

Ao mesmo tempo em que os professores se preocupam em reforçar a importância da presença da escola nas TIs, salientam a relevância da religião tradicional e seu papel na educação das crianças.

[...] uma das coisas que me preocupa hoje nas áreas indigenas também, que a gente precisa resgatar, porque na área em que eu estava existe a religião indígena guarani, que é a principal coisa que tem que existir na área para não perder a cultura, porque a religião é que educa um indio, e em muitas áreas do Brasil hoje, o indio, além de perder a cultura, perde também a religião [...]. (Olívio Jekupe. Ex-professor da T.I. Laranjinha, depoimento publicado em MOTA, 2000, p. 21).

Pensando a importância, expressa pelo grupo, da religião, da cultura e da educação escolar, o Projeto propôs iniciativas institucionais visando a registrar e sistematizar conhecimentos tradicionais, pensar os programas, currículos e calendários escolares formulados para as escolas, com o intuito de contribuir para que sejam considerados aspectos da cultura Guarani nos espaços educativos, 
bem como mobilizar professores, equipes pedagógicas e gestores no sentido de estimular o comprometimento com a cultura indígena na escola.

Contando também com a participação de duas pedagogas guarani como pesquisadoras bolsistas formadas pela UEM, o projeto teve como objetivo central criar condições e estimular o encontro entre tudjás, velhos das três terras indígenas falantes da língua materna e registrar narrativas, histórias e conhecimentos para reapresentá-los às crianças e jovens indígenas por meio de atividades escolares.

Segundo Almeida e Mura (2003), o Tekohá, composto pela terra, mato, campo, águas, animais e plantas, representa o espaço físico onde se realiza a vida Guarani e o Teko (modo de ser guarani). É nesse espaço que se dão as relações familiares e as atividades religiosas, econômicas e outras. Conforme Nimuendaju (1987), o Tekohá deve ser um lugar que reúna condições físicas (geográficas e ambientais) e estratégicas adequadas à vida de todo o grupo com suas famílias extensas.

O Tekohá vem passando por muitas mudanças à medida que os territórios vêm sendo continuamente diminuídos. Segundo Almeida e Mura (2003), este processo promoveu uma interrupção da continuidade territorial com a qual esses indígenas estavam habituados, o que interferiu sobremaneira em suas relações sociais. Conforme os autores, antes da ocupação nos moldes da sociedade europeia, de mercado, não havia delimitação clara de espaço entre essas populações, elas viviam conforme as regras do Teko. As delimitações eram dadas através de elementos geográficos como rios, montanhas, nascentes, vegetação e relações com outros grupos indígenas. A partir da ocupação tiveram que repensar seu território intercambiando ações provenientes da lógica indígena com a não indígena (por exemplo, a divisão por estados e regiões).

Como as condições adequadas à vida Guarani não são facilmente estabelecidas com a redução dos grupos em pequenas áreas degradadas ambientalmente, esses indígenas desenvolvem uma série de estratégias (alianças, retomadas de territórios tradicionais, acesso às políticas públicas) na tentativa de garantir e dar vida ao Teko.

Com a expropriação de seus territórios, assassinatos e doenças, os Guarani do Norte do Paraná foram reduzidos a poucos grupos familiares, sendo forçados a ampliar alianças com os não índios ou indígenas de outras etnias pela via de casamentos. Esta estratégia, somada à redução do Tekoá, às mudanças e ou transferências forçadas por conflitos internos, ao desmatamento, ao abandono das práticas religiosas da opy devido à entrada de ordens religiosas protestantes nas aldeias (BARROS, 2003), e à necessidade de buscarem trabalho nas cidades, contribuiu para que deixassem de falar a língua guarani e, consequentemente de 
produzir e reproduzir grande parte de suas tradições, de forma que os jovens e as crianças vivenciam pouco as experiências culturais dos grupos (FAUSTINO, 2006).

A realidade da vida dos povos indígenas nas TIs da região Norte do Paraná carece de estudos com fontes diversificadas, principalmente orais, de autorias que envolvam os indígenas como os próprios sujeitos da história. Por meio da história oral é possível apreender novos ângulos e perspectivas, com a visão dos sujeitos que participaram diretamente dos acontecimentos históricos.

Segundo Bartomeu Melià (1979), é importante perpetuar em textos escritos a memória, inclusive de tradições orais, como a indígena, em que os conhecimentos passados dos mais velhos para os mais novos representam formas próprias de resistência ou de mudança.

A memória é sabidamente um direito que nem sempre é estendido a todos. Organismos, instituições e suas articulações ideológicas, bem como interesses políticos acabam por selecioná-la, relegando o passado de grupos de menor representação a um subplano, encoberto pelo que se denomina memória oficial. (OLIVEIRA, 2006, p. 3).

Com essa perspectiva, a metodologia do trabalho pautou-se por reuniões comunitárias de planejamento envolvendo lideranças indígenas, pedagogas, professores e os tudjás, velhos. Foi proposta a organização de colóquios e intervenções pedagógicas nas escolas indígenas. Houve um planejamento prévio das atividades, que ocorreram, em parte nas terras indígenas e em parte na UEM, contemplando coleta e registro de elementos da memória dos tudjá, sistematização em forma de textos escritos e material de áudio. Com o apoio de técnicas da história oral, entendida como o trabalho de pesquisa que utiliza fontes orais em diferentes modalidades, optou-se por entrevistas temáticas e histórias de vida.

As entrevistas temáticas são aquelas que versam prioritariamente sobre a participação do entrevistado no tema escolhido, enquanto as de história de vida têm como centro de interesse o próprio indivíduo na história, incluindo sua trajetória desde a infância até o momento em que fala, passando pelos diversos acontecimentos e conjunturas que presenciou, vivenciou ou que se inteirou. Pode-se dizer que a entrevista de história de vida contém, em seu interior, diversas entrevistas temáticas, já que, ao longo da narrativa da trajetória de vida, os temas relevantes para a pesquisa são aprofundados. (ALBERTI, 2005, p. 37).

A utilização da história oral, de acordo com Delgado (2010), é um método, um caminho, um meio para cultivo do conhecimento histórico, não permitindo que tal conhecimento se perca junto com a palavra. Destes resultam 
documentos que se fazem por meio da oralidade, à medida que o sujeito relata seu passado, ativa sua memória e suas recordações, permitindo que se vá além das fontes já existentes.

Segundo Alberti (2005, p. 17), utilizando-se da linguagem oral, parte-se de um projeto, de toda uma organização e preparação, para se trabalhar com entrevistas, depoimentos e narrativas em busca de informações. Os dados e informações coletados passam pelo processo de sistematização por meio da linguagem escrita, articulando, assim, oralidade e escrita como um elemento que pode contribuir com as práticas educativas nas escolas indígenas.

\section{As narrativas}

A questão da oralidade tem para os Guarani um significado muito profundo, pois a palavra define a pessoa, ou seja, as palavras são, para esse grupo, manifestação da aywu, palavra-alma (SCHADEN, 1976; NIMUENDAJU, 1987). A história oral, neste sentido, possibilita a preservação da memória por meio de registro de histórias de vida e de outras narrativas.

O primeiro colóquio sobre História, memória e conhecimentos Guarani Nhandewa no Paraná ocorreu em Maringá, na UEM, em abril de 2010, e contou com a presença de dez tudjás, professores indígenas, estudantes indígenas do ensino superior e equipe interdisciplinar de pesquisadores do PIESP/LAEEUEM. Como forma de estímulo ao início das interlocuções, colocou-se a seguinte questão para o debate: "O que é importante na cultura guarani que deve ser ensinado na escola da TI?”. Seguiram-se três dias de diálogos, estudos, visitas a museus, bibliotecas, parque ecológico, viveiro de mudas, pontos turísticos da cidade, refeições coletivas, consulta a fontes da cultura material e imaterial existentes no LAEE, entrevistas e registros de narrativas.

O colóquio evidenciou que, para os Guarani, o território habitado, chamado Tekohá, compõe grande parte de suas memórias e tem muita importância para a organização sociocultural dos grupos, de forma que seus componentes - como a religiosidade, a palavra, os nomes próprios, a linguagem, as histórias, o trabalho, as roças, os animais, as plantas, a água, as flores, os alimentos, a busca de materiais para o artesanato, as lutas e o acesso às políticas públicas - devem fazer parte dos trabalhos da escola.

Ao serem confrontadas estas questões com os currículos escolares e as práticas educativas presentes nas escolas indígenas das TIs, demonstrou-se a necessidade de aprimorá-los com pesquisas, momentos coletivos entre a comunidade, marcados especificamente com fins de elaboração de materiais pedagógicos. 
Ao serem expostas e analisadas as narrativas e histórias contadas pelos mais velhos que ouviram de seus pais e familiares, pode-se perceber que as práticas indígenas têm um intenso caráter educativo.

Os tudjá contaram histórias com temas variados envolvendo religião, trabalho, viagens, parentes, sentimentos, mortos, medos, almas... Todas enfatizam a importância da crença, de acreditar no que foi revelado por Nhanderu (o pai maior). Alguns tudjá que são yviraidjá (espécie de ajudante dos txamór) estavam com cocares, mbaracas, colares, e, além das histórias contadas, dançaram e rezaram na UEM. Alguns expuseram conhecimentos tradicionais, mas não dançaram, alegando fazer parte de outra religião (evangélica) e não desejarem mais praticar a religião antiga.

Assim, os colóquios revelaram questões profundas que envolvem a cultura e suas transformações após o contato, mas que necessitam de estudos aprofundados para serem melhor compreendidas.

\section{O Nimongarai}

Um dos eventos realizados pelo Projeto foi uma cerimônia religiosa importantíssima para a cultura Guarani, o Nimongarai, que é feito para batizar, consagrar. Segundo o professor Teodoro Tupã, ocorre duas vezes ao ano, na opy, sendo uma para batizar as sementes a serem plantadas e a outra para consagrar a produção das roças. Para batizar crianças e revelar seus nomes, a família que tem criança com cerca de seis meses a dois anos de idade, para nomear tem que pedir e ajudar a preparar a cerimônia.

A opy tem grade significado para os Guarani. É feita com madeira sagrada, como o cedro, e é, tradicionalmente, o local da prática da religião e de encontros em que crianças e jovens aprendem as tradições. As celebrações representam importante mecanismo de equilíbrio e alívio das tensões presentes no interior dos grupos, “[...] pois, através dos rezadores e de outras figuras importantes como as ñandecy, (rezadoras), são refletidos para o plano religioso problemas como o faccionalismo e desavenças pessoais" (BARROS, 2003, p.11).

A opy é construída assim que um grupo familiar extenso se estabelece em um tekoá, sendo usada para as cerimônias, mais comumente as chamadas poray (canto e dança), havendo diversos outros nomes específicos para cada cerimônia.

Por escolha dos participantes indígenas do Projeto, o Nimongarai realizouse na TI Pinhalzinho nos dias 08 e 09 de julho de 2010 envolvendo cerca de trinta dias entre organização, período de chegada dos tudjá e demais convidados 
à TI, preparativos de alimentos tradicionais, preparação espiritual dos txamói e da Opy existente na comunidade, cujo pátio foi preparado com mudas de palmeira de jerivá, plantas frutíferas e flores plantadas em belíssima simetria com o jerivá, planta sagrada para os Nhandewa, formando um "corredor" até a entrada da $O p y$.

Rituais de Nimongarai foram descritos por CurtNimuendaju (1981), Schaden (1976), Melià (1991), Arguello (1998) e outros. Em quase todas as descrições consta que a cerimônia ocorre no mês de janeiro. Quando perguntamos aos tudjá e professores indígenas por que escolheram fazer em julho, a resposta foi que é possível fazer nessa data devido à safrinha de milho, e que para acontecer o Nimongarai este tem que ser marcado, convocado pela liderança de um grupo familiar, como ocorreu em Pinhalzinho, partindo do cacique Sebastião Alves.

A professora Nilza Maria do Tekoá Vera Tupã'i, explicou que o mês de julho ou meados desse período significa também a chegada do Ano Novo para os Guarani. Esse não tem data fixa, ocorre quando a natureza se renova com as chuvas e as primeiras árvores florescem, dura cerca de noventa dias. Geralmente, a primeira árvore a florescer em uma terra nova torna-se a árvore sagrada para o grupo.

No planejamento da atividade ficou definido que tudo seria registrado e formaria um documentário, destinado ao acervo das escolas indígenas, às comunidades envolvidas e às fontes de pesquisa do LAEE/UEM. Essa decisão foi tomada porque as cerimônias de Nimongarai no Norte do Paraná são raras. Na TI Laranjinha a explicação da ausência das celebrações tradicionais é a conversão da quase totalidade dos grupos à CCB (Congregação Cristã do Brasil) (BARROS, 2003; FAUSTINO, 2006). Nas demais terras não ocorre porque faltam txamói.

O projeto oportunizou a reunião de três txamói, sendo uma mulher e dois homens: Dona Almerinda da Silva Norato, Guarani Nhandewa da TI Laranjinha, que vivia em Iwy Porã e tinha 78 anos; o senhor José da Silva, Guarani Kaiowa, morador antigo da TI Pinhalzinho, com 71 anos; e o senhor Osvaldo Tupã Miri, da TI Ava-Guarani de São Miguel, com 75 anos. O senhor Osvaldo faleceu em 2011 e não residia nas TIs envolvidas no Projeto, mas foi chamado pelo cacique de Pinhalzinho devido às redes de parentesco que os grupos indígenas de uma mesma etnia e território estabelecem entre si.

O Projeto apoiou o deslocamento dos txamói para o Pinhalzinho. O grupo solicitou ainda ajuda para adquirir três litros de mel, três quilos de canjica, duas sacas de milho verde e quatro quilos de peixe (cascudo ou bagre). Os alimentos tiveram de ser comprados, pois as TIs não conseguem mais produzi-los ou extraílos, por causa da devastação do solo, do desmatamento e da poluição dos rios. O cacique explicou que antigamente, quando ia acontecer o Nimongarai os parentes 
traziam alimentos. $\mathrm{O}$ mel era retirado pelos rapazes. Segundo as lideranças e professores indígenas, a falta desses alimentos sagrados e a dificuldade de adquiri-los é um dos motivos que dificultam a realização do Nimongarai nas TIs.

Perguntamos ao professor indígena Reginaldo Alves a causa das bruscas mudanças dos elementos tradicionais e das influências sobre a comunidade, ao que nos respondeu: "[...] Os Guarani têm capacidade de acompanhar as mudanças sem perder os aspectos da sua cultura".

O milho tradicional Guarani, o avaxi, de extrema relevância cultural, praticamente inexiste nas TIs envolvidas no Projeto. Os professores, ao se encontrarem com professores de outras regiões e estados, nos cursos de formação, têm conseguido recuperar as sementes, mas seu cultivo fica comprometido na polinização devido à existência das espécies híbridas no entorno ou na própria TI. O mel e os peixes também não se conseguem mais.

A canjica, o peixe e o bolo de milho foram preparados da forma tradicional, sem a adição de sal, açúcar, gorduras ou temperos, e ingeridos nos três dias que antecederam a cerimônia, pois são fundamentais para purificar os corpos dos txamói que receberão das divindades a inspiração, os nomes de uma das quatro regiões, os fundamentos da cultura Guarani.

Há quatro regiões onde residem diferentes deuses. O professor Teodoro Tupã explica que são como o Norte, Oeste, Leste e Sul. Cada uma delas é constituída por divindades e representa a morada dos deuses. Os nomes provêm delas, determinando a pessoa, o que ela é e sua missão. Os txamói conhecem esses fundamentos, porém lamentam que hoje, devido às grandes perdas culturais causadas pela falta de terras, afirmam que nenhum txamói consegue ter o pleno domínio e conhecimento das quatro regiões.

No dia 08 de julho, com tudo preparado, os Guarani provenientes do grupo familiar do senhor Sebastião Lucas chegaram, inclusive os que moram em outras terras e alguns estudantes universitários que moram nas cidades.

Ao lado direito da opy acendeu-se uma fogueira, alimentada com lenha a noite toda. Em sua volta foram colocados bancos e algumas pessoas sentavam e conversavam ao redor do fogo, que é, para a cultura Guarani, o principal elemento de ligação do universo.

Algumas pessoas sentavam-se dentro da opy, conversavam com os txamói. Dona Almerinda, com a ajuda de Júlia, moradora antiga do Pinhalzinho, contou-nos parte da história dos gêmeos fundadores, Djikokawa e Kotxovy ${ }^{1}$. Ao final da

\footnotetext{
${ }^{1}$ Trata-se do mito fundador dos Nhandewa, com versões registradas por Curt Nimuendaju na obra As lendas da criação e destruição do mundo como fundamentos da religião dos Apapocúva-Guarani, por Miguel Alberto Bartolomé, em Chamanismo y religión entre los Ava-Katu-Ete e outros.
} 
narrativa disse sentir-se preocupada, pois, como está doente e fraca, tem receio de morrer logo e não passar a reza dela para alguém mais velho. Informou que a pessoa que recebe a reza tem que resistir e ser forte. Nos dias que precederam a celebração o senhor Osvaldo Tupã Miri passara longos períodos no interior da opy, em absoluto silêncio.

Em frente à casa, com cerca de nove metros de distância, havia uma cruz ladeada por paus fincados no chão e um jirau com uma vasilha de bebida preparada com mel, água e cascas de madeira. No interior da opy, em seu centro, dispunham-se instrumentos musicais e adornos.

Ao entardecer, os cantos e a dança se iniciaram com os participantes em fila, uma de homens e meninos, outra de mulheres, meninas e crianças de colo. Estas batiam seus takuá, taquara preparada para este fim. Alguns homens tocavam violão, mbaracas e chocalho e usavam kanguaá, cocares feitos com penas de galinha e tingidos com anilina. Cantos e danças eram sincrônicos e longos. Em alguns momentos as filas se juntavam e davam voltas no pátio passando pelo interior da opy. A dança durou cerca de seis horas. Alguns Guarani assistiam sentados ao lado da fogueira. Entre as onze horas e a meia-noite fez-se uma pausa.

Com acolchoados e colchonetes, alguns dormiram na opy, outros foram para suas casas, nos arredores. Por volta das quatro horas da manhã a fogueira foi realimentada e reiniciaram-se o canto e a dança com novas formações em filas. Os txamói Osvaldo e José da Silva, bem como o cacique Sebastião, passavam pelas filas aspergindo a fumaça do petyngua, cachimbo repassado a alguns dos adultos presentes.

Dona Almerinda se posicionada em frente às filas, fazia gestos e dava conselhos às crianças, aos jovens e às mães com seus bebês de colo. Falava frases curtas, parte em guarani, parte em português, com repetições. Das frases proferidas e repetidas apresentamos três: "[...] a roça de vocês hoje é a escola", "[...] tomem cuidado com carros e motos, olhem bem quando andarem na cidade". Para as meninas ela dizia "[...] quem casa com homem que bebe não casa bem".

Mulheres não indígenas mais velhas, casadas com indígenas pertencentes ao grupo familiar do cacique Sebastião, tinham as mesmas habilidades com o takuá, canto e orações compondo as filas juntamente com os demais. No decorrer da dança alguns se preparavam, em fila, para receber os nomes, e as duplas de padrinhos se formaram entre os mais velhos e as lideranças. Houve certa correria, pois os nomes todos deveriam ser revelados antes de o sol nascer. Nossa equipe assistira à cerimônia sentada ao redor da oppy, e em alguns momentos dentro da opy, observando e registrando. Quando as duplas de padrinhos se prepararam o cacique se dirigiu a nós, pesquisadores do LAEE/UEM, e anunciou que também seriamos batizados e que deveríamos entrar na fila. Naquele momento éramos dois professores, dois alunos e um técnico de filmagem. 
Mais de uma hora transcorreu até que todos tivessem os nomes anunciados pelos txamói, que se revezavam nas filas. O momento final da cerimônia é de beleza e harmonia indescritíveis. Preocupávamo-nos em saber se tudo poderia ser filmado ou se preferiam que alguns momentos não fossem registrados. Todas as respostas foram unânimes e eram dadas pelo cacique e suas lideranças principais: "Pode filmar tudo!".

Poucos minutos antes do nascer do sol o cacique pediu que chamássemos o técnico de filmagem de nossa equipe para também ser batizado. O nome dado a ele foi mboporãdju. Buscamos saber o significado e obtivemos como resposta: "Aquele que guarda".

$\mathrm{O}$ professor indígena Reginaldo Alves registrou em um caderno todos os nomes recebidos pelas crianças e jovens indígenas e também pela equipe de pesquisadores da UEM, discutindo a grafia com alguns dos presentes que sabiam escrever um pouco na língua Guarani. Isso nos revelou a importância da escrita para a cultura Guarani na atualidade.

\section{As intervenções pedagógicas nas escolas indígenas}

Todas as histórias, as narrativas e os ensinamentos sobre plantas medicinais e remédios registrados no Projeto apresentam alto teor educativo, tanto em termos de conteúdo como de método. Tradicionalmente, a educação Guarani se dá por múltiplas linguagens contidas nas vivências do grupo familiar. A observação, os gestos, a participação nas atividades de trabalho, religiosas e de laser representam, para a criança, a inserção em um rico e complexo mundo cultural. É a educação pelo olhar, ouvir, participar, repetir, pensar, criar e recriar.

Ouvir atentamente as histórias, pensar sobre elas, ter interesse, perguntar e aprender são essencial na cultura Guarani. Teodoro Tupã explicou que as histórias são contadas aos poucos, despertam a curiosidade infantil e as crianças precisam perguntar para saber mais; precisam ficar junto aos adultos, participar das "rodas" de conversa, ouvindo em silêncio.

Para Lev Semenovich Vigotski, estudioso russo que elaborou, juntamente com Alexei Nikolaevich Leontiev e Alexander Romanovich Luria, a Teoria Histórico-Cultural, a cultura é fator determinante nos processos de aprendizagem e desenvolvimento infantil. Com base no materialismo histórico-dialético, estes teóricos desenvolveram pesquisas que evidenciaram que a educação se dá nas diferentes interações com o meio e com o outro. Ao nascer, a criança se insere em um ambiente organizado culturalmente e vai, em um longo processo, apropriando-se do conhecimento à medida que participa das atividades organizadas e mediadas pelos mais velhos, conhecedores e experientes, do grupo social a que pertence. 
Segundo essa teoria, a escola representa um espaço socialmente organizado e contribui sobremaneira para a elaboração de novos conhecimentos. $\mathrm{Na}$ escola, o professor é fundamental, pois planeja e organiza formas de interação que determinarão a apropriação e a transferência de conhecimento, ampliando as áreas de estudo, aprendizagem e criação dos estudantes. Nesse processo o professor atua, assim como os mais velhos experientes da família, como mediador, ajudando as crianças e jovens a desenvolver conhecimentos. A escola deve constituir-se como oportunidade para a criança acessar o mundo da cultura escrita e usufruir também dos bens culturais codificados por essa linguagem. Para Vigotski (2009, p. 67), “[...] a verdadeira tarefa da educação não é a de infligir prematuramente a língua adulta, mas a de ajudar a criança a elaborar e formar uma língua literária própria.”

Na cultura Guarani destaca-se o papel da mediação dos adultos na aprendizagem da criança e a importância do brincar, o nhemboarai. Ao relatar as brincadeiras tradicionais, o professor Teodoro Tupã informa que estas eram planejadas, organizadas e coordenadas por adultos. Os brinquedos são feitos pelos mais velhos, enquanto a criança observa atentamente o processo. Mencionou a peteca de palha de milho, uma brincadeira de meninas; o arco e flecha, uma brincadeira de meninos com mais de 8 anos; o esconde-esconde, brincadeira tradicional com variações em que o adulto responsável esconde um pedacinho de vara ou faz um sinal em determinado lugar, árvore ou chão, e as crianças têm que encontrá-lo. Nesse jogo há diversas regras a serem seguidas, como a divisão por idade e sexo. Para o professor Teodoro Tupã, "[...] todo jogo é relacionado à cultura. Através do jogo a criança aprende a regra da nossa cultura".

A Teoria Histórico-Cultural imputa grande valor ao brincar e ao brinquedo. Vigotski desenvolveu muitos estudos sobre a questão, afirmando que o brincar desempenha um importante papel no desenvolvimento da criança e na aprendizagem das regras sociais.

Dessa forma as ações do projeto, ao se estenderam para as escolas, enfatizam a oralidade, os jogos e as brincadeiras. Parte do material das narrativas foi sistematizada e apresentada às crianças e jovens nas instituições escolares. Com o apoio e participação das equipes pedagógicas, professores indígenas e não indígenas, a ação se deu por meio de roda de conversas, contação de histórias com fantoches, diálogos e ilustrações pelas crianças, criando situações para que os participantes demonstrassem seus conhecimentos por diferentes formas de expressão, interagindo com os conteúdos apresentados.

Como as comunidades têm a língua portuguesa como língua materna, os professores optaram pela ação pedagógica nessa língua e iniciaram um trabalho de versão das narrativas contadas em português na forma escrita do guarani nhandewa, para assim constituírem um material bilíngue. 
No contexto da política educacional atual, A LDBEN (Lei de diretrizes e Bases da Educação Nacional), Lei 9394/96, seu artigo 78 estabelece ser de responsabilidade dos estados e da União estimular a cultura e desenvolver programas integrados de ensino e pesquisa, para proporcionar a educação escolar bilíngue e intercultural aos povos indígenas com o intuito de:

$1^{\circ}$, fortalecer as práticas socioculturais e a língua materna de cada comunidade indígena; $2^{\circ}$, manter programas de formação de pessoal especializado, destinado à educação escolar nas comunidades indígenas; $3^{\circ}$, desenvolver currículos e programas específicos, neles incluindo os conteúdos culturais correspondentes às respectivas comunidades; e $4^{\circ}$, elaborar e publicar sistematicamente material didático específico e diferenciado. (BRASIL, 1996, p. 33).

Os professores encaminham suas ações nas escolas com o respaldo dessa legislação e das decisões internas das comunidades quanto ao uso da língua indígena no espaço escolar. O material resultante do projeto foi preparado e revisado pelos professores indígenas para ser publicado e assim compor tanto o acervo de materiais escritos diferenciados e específicos da cultura Guarani Nhandewa como um acervo de fontes pesquisas sobre a história dos Guarani no Paraná.

\section{Considerações finais}

$\mathrm{O}$ artigo procurou evidenciar a situação em que vivem os povos indígenas no Brasil e sua relação com as políticas públicas decorrentes das decisões internacionais, afirmando que, após 1948, no contexto da Guerra Fria e do combate ao comunismo, constituiu-se um discurso pela paz, tolerância e diversidade cultural. Esse discurso foi amplamente disseminado pelos organismos e agências internacionais e se intensificou na elaboração de leis, no contexto da crise estrutural do sistema capitalista que aprofundou situações de pobreza e exclusão.

Tendo sido dizimados, aldeados em pequenas parcelas de terras improdutivas e controladas pelo sistema, os sobreviventes indígenas perderam grande parte de suas tradições, adaptando-se à dependência, à venda de mão de obra no mercado de trabalho precarizado e ao consumo de produtos industrializados. Essa situação praticamente inviabilizou o uso da língua, as formas tradicionais de trabalho, as práticas religiosas e os complexos sistemas de educação indígena nos grupos familiares.

Lutando pela sobrevivência e pela manutenção e/ou recuperação do que lhes sobrou de terras, os guarani tentam manter e revitalizar aspectos das tradições. Dispondo de uma legislação que permite o uso das línguas e conhecimentos indígenas na escola, algumas comunidades buscam apoio institucional nesse processo. 
No contexto internacional das ações afirmativas e políticas compensatórias, foram estabelecidas cotas ou vagas sobressalentes para ingresso de indígenas no Ensino Superior, e assim, temáticas relativas a estes povos despertam maior interesse na pesquisa e extensão acadêmica, dando origem a projetos com participação das comunidades.

A situação da escola nas terras indígenas no Paraná depende da situação jurídica da terra, pois aquelas recém-conquistadas ou em litígio apresentam situações muito precárias de educação, não oferecendo as mínimas condições de estrutura para o desenvolvimento de um bom trabalho pedagógico. Dependem exclusivamente da boa vontade de professores índios e não índios e de técnicos governamentais, que se esforçam para implementar nas TIs uma escola bilíngue e intercultural.

O Projeto permitiu um trabalho conjunto com os profissionais da educação indígenas formados pela Universidade Estadual de Maringá no curso de Pedagogia que hoje atuam como pedagogas em duas escolas, bem como, professores indígenas que, de alguma maneira, têm dado continuidade ao registro das narrativas dos tudjás e sua apresentação às crianças cujas comunidades não tenham atividades na Opy e careçam da existência de Txamoi.

Com o apoio do Programa Observatório da Educação o Projeto não se encerrou e as lideranças solicitaram a incorporação de registros fotográficos, escritos e áudio que devem ser feitos nos rios e nas matas que restam no entorno das terras indígenas, destacando os nomes indígenas das plantas, dos remédios, das frutas, raízes, cipós e sementes, bem como seus usos tradicionais pela comunidade no artesanato, nos remédios e na alimentação, com o intuito de constituir um vasto e diversificado material de ensino para as escolas indígenas.

\section{Referências}

ALBERTI, V. Manual de história oral. 3. ed. Rio de Janeiro: Editora FGV, 2005.

ALMEIDA, R. T. de; MURA, F. Guarani Kaiowa e Ñandeva. In: Enciclopédia Povos Indígenas no Brasil. Instituto Socioambiental, 2003. Disponível em: <www.socioambiental. org >. Acesso em: 30 mar. 2011.

ARGÜELLO, C. G. C. O rito de nominação numa aldeia Mbyá-Guarani do Paraná. Diálogos, Maringá, v. 2, n. 2, p. 201-216, 1998.

BARROS, M. C. D. M. A missão Summer Institute of Linguistics e o indigenismo latinoamericano: história de uma aliança (décadas de 1930 a 1970). Revista de Antropologia, São Paulo, v. 47, n. 1, p. 45-85, 2004. DOI: 10.1590/S0034-77012004000100002

BARROS, V. E. N. Da casa de rezas à Congregação Cristã do Brasil: o petecostalismo Guarani na Terra Indígena Laranjinha/PR. 2003. Dissertação (Mestrado em Antropologia Social) - Universidade Federal de Santa Catarina, Florianópolis, 2003. 
BARTOLOMÉ, M. A. Chamanismo y religión entre los Ava-Katu-Ete. 2. ed. Assunção: Centro de Estudios Antropológicos de la Universidad Católica, 1991.

BENGOA, J. Desarrollo con identidad: la cuestion del desarrollo indígena en América Latina. In: UQUILLAS, J. E.; RIVERA, J. C. Pueblos Indígenas y desarrollo em América Latina. Washington: Banco Mundial, 1993. p. 73-82.

BRASIL. Lei no 9.394, de 20 de dezembro de 1996. Estabelece as Diretrizes e Bases da Educação Nacional. Diário Oficial da União, Brasília, 23 dez. 1996. Disponível em: <http://www.planalto.gov.br/ccivil_03/LEIS/19394.htm>. Acesso em: 13 mar. 2012.

CIMI - Conselho Indigenista Missionário. Violência contra os povos indígenas no Brasil. 2006. Disponível em: <http://www.estadao.com.br/ext/especiais/2008/04/parte1.pdf>. Acesso em: 12 mar. 2010.

CUCHE, D. A noção de cultura nas ciências sociais. Bauru: EDUSC, 1999.

DELGADO, L. de A. N. História Oral: memória, tempo, identidades. In: História oral, memória, identidades. 2. ed. Belo Horizonte: Autêntica, 2010. p. 9-66.

DREMINSKI, J. L. Proteção das sementes crioulas indígenas como direito humano. 2011. 169 f. Dissertação (Mestrado em Direito) - Pontifícia Universidade Católica do Paraná, Curitiba, 2011.

ESTRATÉGIA de participação dos povos indígenas no projeto multissetorial para o desenvolvimento do Paraná. Curitiba, 2012. Disponível em: <http://www.sepl.pr.gov.br/ arquivos/File/EPPI_ABR_2012_Indigena.pdf>. Acesso em: 18 maio 2012.

FAUSTINO, R. C. Política educacional nos anos de 1990: o multiculturalismo e a interculturalidade na educação escolar indígena. 2006. 334 f. Tese (Doutorado em Educação) - Universidade Federal de Santa Catarina, Florianópolis, 2006.

GAGLIARDI, J. M. O indígena e a República. Hucitec: São Paulo, 1989.

GARCIA, E. F. O projeto pombalino de imposição da língua portuguesa aos índios e a sua aplicação na América meridional. Tempo, Niterói, v. 12, n. 23, p. 23-38, 2007. DOI: 10.1590/S1413-77042007000200003

GIROTTTO, R. L. O Serviço de Proteção aos Índios e o estabelecimento de uma política indigenista republicana junto aos índios da reserva de Dourados e Panambizinho na área de educação escolar (1929 a 1968). 2007. 250 f. Tese (Doutorado em História) Universidade Estadual Paulista "Julio de Mesquita Filho", Assis, 2007.

GRIZZI, D. C. S.; SILVA, A. L. da. A Filosofia e a Pedagogia da Educação Indígena: um resumo dos debates. In: COMISSÃO PRÓ-ÍNDIO (SP). A questão da educação indígena. São Paulo: Brasiliense, 1981. p. 15-29.

HUNTINGTON, S. P. Choque do futuro. Reflexões para o futuro - Veja 25 anos. Rio de Janeiro: Abril Cultural, 1993.

ISA - INSTITUTO SOCIOAMBIENTAL. Povos indígenas no Brasil. Disponível em: <http://pib.socioambiental.org/pt/povo/guarani-nandeva>. Acesso em: 13 mar. 2012.

MELIÀ, B. Educação indígena e alfabetização. São Paulo: Loyola, 1979. (Coleção "Missão Aberta"). 
El Guarani: experiencia religiosa. Asunción: CEADUC/CEPAG, 1991. (Biblioteca Paraguaya de Antropología, 13).

MOTA, L. T. O aço, a cruz e a terra: índios e brancos no Paraná provincial (1853-1889). 1998. 530 f. Tese (Doutorado em História) - Universidade Estadual Paulista, Assis, 1998.

As cidades e os povos indígenas: mitologias e visões. Maringá: Eduem, 2000.

MOTA, L. T.; NOELLI, F. S. Exploração e guerra de conquista dos territórios indígenas nos vales dos rios Tibagi, Ivaí e Piquiri. In: DIAS, R. B.; GONÇALVES, J. H. R. (Org.). Maringá e o Norte do Paraná: estudos de história regional. Maringá: EDUEM, 1999. p. 21-50.

NIMUENDAJU, C. As lendas da criação e destruição do mundo como fundamentos da religião dos Apapocúva-Guarani. Tradução de Charlotte Emmerich e Eduardo B.Viveiros de Castro. São Paulo: HUCITEC; Editora da Universidade de São Paulo, 1987. (Coleção Ciências Sociais).

As lendas da criação e destruição do mundo como fundamentos da religião dos Apapocúva-Guarani. Tradução por Charlotte Emmerich; Eduardo B. Viveiros de Castro. São Paulo: HUCITEC; Editora da Universidade de São Paulo, 1981. (Coleção Ciências Sociais).

OIT - Organização Internacional do Trabalho. Convenção $\mathbf{n}^{\mathbf{0}} 107$ de 05 de junho de 1957. Disponível em: <http://6ccr.pgr.mpf.gov.br/legislacao/legislacao-docs/convencoesinternacionais/conv_intern_02.pdf>. Acesso em: $1^{\circ}$ fev. 2004.

OLIVEIRA, A. P. de P. L. de. Memórias indígena e negra na Zona da Mata Mineira. São João Nepomuceno: Museu de Arqueologia e Etnologia Americana/ Universidade Federal de Juiz de Fora, 2006. Disponível em: < http://www.ufff.br/maea/files/2009/10/propostafinal. pdf>. Acesso em: 21 fev. 2011.

ONU - Organización de las Naciones Unidas. Consejo Económico y Social. Educación multicultural e intercultural y protección de las minorias. Comissión de Derechos Humanos. Grupo Trabajo sobre lãs Minorías, maio 1999. Disponível em: <http://www. unhchr.ch/Huridocda/Huridoca.nsf/TestFrame/90c12425670ce1bc802568fd002ec58c?Op endocument>. Acesso em: $1^{\circ}$ abr. 2002.

ONU - Organización de las Naciones Unidas. Consejo Económico y Social. Declarción sobre lós Derechos de lãs persomas pertenecientes a minorias nacionales o étnicas, religiosas y linguísticas. ONU, 1992.

PACHECO DE OLIVEIRA, J.; FREIRE; C. A. da R. A presença indígena na formação do

Brasil. Brasília: Ministério da Educação, Secretaria de Educação Continuada, Alfabetização e Diversidade; LACED/Museu Nacional, 2006.

PARANÁ. Secretaria de Estado da Educação/Superintendência da Educação. Plano Estadual de Educação - PEE PR: Uma construção coletiva. Curitiba, 2005. Disponível em: <http://www.diaadiaeducacao.pr.gov.br/portals/portal/pee/construcao_coletiva.pdf>. Acesso em: 26 set. 2009.

SCHADEN, E. Educação indígena: problemas brasileiros. São Paulo: Abril, 1976.

Religião Guarani e Cristianismo. Revista de Antropologia, São Paulo, v. 25, p. 1-24, 1982. 
UNESCO; CEPAL; OEA. Declaración de México. Aprovada por la Conferencia Regional de Ministros de Educación y de Ministros Encargados de la Planificación Económica de los Estados Miembros de América Latina y del Caribe. México: UNESCO, 1979.

VIGOTSKI, L. S. Imaginação e criação na infância: ensaio psicológico. São Paulo: Ática, 2009.

Recebido em 15/06/2012

Versão final recebida em 20/10/2012

Aceito em 05/12/2012 